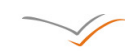 \\ VERSITA 10.2478/v10310-012-0019-0 \\ Ovidius University Annals of Chemistry \\ Volume 23, Number 1, pp.115-120, 2012

\section{Estimation of heavy metals in medicinal plants and their infusions} \\ Diana DIACONU ${ }^{\mathrm{a}}$, Rodica DIACONU* ${ }^{\mathrm{b}}$ and Tinca NAVROTESCU ${ }^{\mathrm{c}}$ \\ ${ }^{a}$ Department of Analytical Chemistry, Faculty of Pharmacy, University of Medicine and Pharmacy "Gr.T.Popa" of \\ Iaşi, 16 Universității Street, 700115, România \\ ${ }^{b}$ Department of Chemistry, Regional Center of Public Health Iaşi, $14 \mathrm{~V}$. Babes Street, 700465, România \\ c. Department of Microbiology, "Apollonia” University, 2 Stefan cel Mare Street, Iaşi, România
}

\begin{abstract}
Medicinal plants and their extracts deserve special attention because of the important influence they have to human health. There are easily contaminated with metals during growth, development and processing. The aim of this study was to achieve the quantitative determination of metallic elements $(\mathrm{Cu}, \mathrm{Cr}, \mathrm{Cd}, \mathrm{Fe}, \mathrm{Mn}, \mathrm{Zn}, \mathrm{Pb})$ in some medicinal plants including Mentha piperita L., Matricaria camomilla L., Hypericum perforatum L., Achillea millefolium L., Thymus serpillum, Capsella-bursa-pastoris L., Urtica dioica L., Primula veris L., Plantago major L., Taraxacum officinalis L., and their infusions, using flame absorption spectrometry. The highest concentration of metal in medicinal plants was that of iron $333.22 \pm 35.18 \mathrm{mg} \mathrm{Kg}^{-1}$ and zinc $244.90 \pm 32.13 \mathrm{mg} \mathrm{Kg}^{-1}$. Metal content in the powdered medicinal plants was in descending order: $\mathrm{Fe}>\mathrm{Zn}>\mathrm{Mn}>\mathrm{Cu}>\mathrm{Cr}$; $\mathrm{Pb}$ and $\mathrm{Cd}$ were present in minor amounts. Analysis of plant infusions showed transfer of heavy metals during extraction procedure. Monitoring the content of mineral elements in medicinal plants and their boiling water extracts is of high importance because some heavy metals in large quantities in the body may have a toxic effect.
\end{abstract}

Keywords: medicinal plants, infusions, heavy metals.

\section{Introduction}

The use of medicinal plants (herbs) has spread not only in the developing countries but also in the industrialized one, as a complementary way to treat and to prevent illness [1-3]. These herbs contain considerable amounts of mineral constituents $[4,5]$. Some metals as $\mathrm{Ca}, \mathrm{Mg}$ an $\mathrm{Zn}$ have reported to be essential for human health, where as other as $\mathrm{Pb}, \mathrm{Cd}$, and $\mathrm{Al}$ has been identified as toxic [6-8]. There is only little knowledge about the potential influence of metals on pharmacological effects of natural drugs obtained from these plants. Metal binding to pharmacologically active substances, or indirectly by influencing bioavailability pharmacokinetics, are possible of metal influences.

The geological background of heavy metals in medicinal plants is low but, with the activity of human, soil, water, air and plants are polluted by metals, in some cases, and even effect human health through the food chain $[9,10]$.

This study has the following objectives:
- to determine the level of heavy metals elements such as $\mathrm{Cu}, \mathrm{Cr}, \mathrm{Cd}, \mathrm{Fe}, \mathrm{Mn}, \mathrm{Zn}$ and $\mathrm{Pb}$ in ten medicinal plants that increase in spontaneous flora of Romania;

- to estimate the concentration of each of these elements after infusion of these plant materials with boiling water;

- to emphasize possible correlations between the levels of heavy metals in dry plant material and their infusions;

- to calculate extraction coefficients to assess extraction efficiency of metals into tea infusions.

\section{Experimental}

\subsection{Plant material.}

Medicinal plant samples were collected in spring-summer period (2009-2010 years) from areas unaffected by pollution, species that grown in East region of Romania (Moldova) and are traditionally used in alternative medicine. Plant specimens were authenticated by botanists.

The following medicinal plants were sampled: 
1. Mentha piperita L (MP) - Peppermint - herb

2. Matricaria camomilla L (MC) - Chamomile flowers

3. Hypericum perforatum L (HP) - St. John-s wort - herb

4. Achillea millefolium L (AM) - Common Yarrow - herb

5. Thymus serpillum (TS) - Wild thyme - herb

6. Capsella bursa - pastoris (CP) - Shepherd's purse - herb

7. Urtica dioica L (UD) - Stinging nettle -leaves

8. Primula veris L (PO) - Cowslip - flowers

9. Plantago major L (PL) - Common plantain - leaves

10. Taraxacum officinalis $\mathrm{L}(\mathrm{P})-$ Common dandelion flowers.

\subsection{Sample preparation}

Tea plant sample preparation. The plant samples were thoroughly washed with de-ionized water to remove dust and other particles, then dried at room temperature and grounded to fine powder. These dry raw materials were used for analytical procedure.

Tea infusion preparation. For this study we used the common practice for serving tea - direct boiling of the medicinal herb in boiling water: 100 $\mathrm{mL}$ of distilled water was boiled in a beaker on a hot plate, and exactly $2 \mathrm{~g}$ of plant power were added in the boiling water and allowed to boil for 5 minute. The cooled for 5 minute and filtered to obtain the infusion. Three such infusions were prepared from each medicinal plants.

Digestion of medicinal plants. Powder of medicinal herbs was digested through wet digestion method: $1 \mathrm{~g}$ sample of each plant was weighed in a beaker, $10 \mathrm{~mL}$ of concentrated $\mathrm{HNO}_{3}$ was added and allowed to stand overnight. Solution was heated in a water bath until the production of red nitrous oxide fumes had not been ceased. $4 \mathrm{~mL}$ of $70 \% \mathrm{HClO}_{4}$ was added and mixture was heated again to evaporate into small volume and filtrated through Whatman filter paper. The solution made up to volume a $50 \mathrm{~mL}$ with distilled water. Digestion of reagent blank was performed in parallel with tea samples and infusions.

Digestion of tea samples $20 \mathrm{~mL}$ of tea infusion was transferred in the flask and heat to reduce volume. $5 \mathrm{~mL}$ of 5:1 $\mathrm{HNO}_{3} / \mathrm{HClO}_{4}$ was added to residue and digested for two hours at $300^{\circ} \mathrm{C}$ on a Kjeldahl digestion apparatus. The digestion made up to $50 \mathrm{~mL}$ with distiller water. The reagents were p.a. purity for the preparation of the solutions and distilled water was used in all cases.

\subsection{Method of analysis}

Seven trace elements $\mathrm{Cu}, \mathrm{Cr}, \mathrm{Cd}, \mathrm{Fe}, \mathrm{Mn}, \mathrm{Pb}$ and $\mathrm{Zn}$ were determined in the herbs and their infusions consumed for medicinal purposes.

Element concentrations in the medicinal herbs and their infusions were determined by flame-atomic absorption spectrophotometry (FAAS) with airacetylene. Stock standard solution containing 1000 $\mathrm{mg} / \mathrm{L}$ in $2 \% \mathrm{HNO}_{3}$ of metals $\mathrm{Cu}, \mathrm{Cr}, \mathrm{Cd}, \mathrm{Fe}, \mathrm{Mn}$, $\mathrm{Zn}, \mathrm{Pb}$ were used for preparation of calibration standards and in spiking experiments. The correlation coefficients of calibration curve for analytes were higher 0.98 which assured a linearity of response over the range of concentrations used.

2.4. Recovery tests

A recovery test of analytical procedure was performed by spiking dry plant material $(0.5 \mathrm{~g})$ with metal standards (the individual $1000 \mathrm{mg} / \mathrm{L}$ standard, Merck, Germany) according to the original concentrations of the spiking samples, to get to concentration in range of $10-500 \mathrm{mg} / \mathrm{kg}$ dry plant. These samples were analyzed by FAAS to get to the recovery of the method. Acceptable recovery were obtained (85-110\%) for all of the studied heavy metals.

\subsection{Statistical analysis of data}

To check whether there are a significant differences in metal contents between medicinal plants was used a one way ANOVA tests.

\section{Results and discussions}

\subsection{Evaluation of analytical method}

The efficiency of the method was assessed by spiking both tea herbs and tea infusion samples with known amounts of metals. Recovery was calculated using equation bellow:

$\%$ Recovery $=$

$\frac{\text { metal content of spiked sample-metal content of non spiked sample }}{\text { the expected metal content }} \times 100 \%$

The recovery values for the plant samples are given in Table 1.

These results show the validity of this method for dray plant material (recovery in range between $82.45-102.3 \%)$. 
For infusions, our results revealed that the studied elements can be accurately determined by the proposed method.

Table 1. Recovery of heavy metals from plant material (Matricaria camomilla)

\begin{tabular}{|c|c|}
\hline Metal & Recovery* \\
\hline $\mathrm{Fe}$ & $102.31 \pm 13.33$ \\
\hline $\mathrm{Zn}$ & $96.23 \pm 3.68$ \\
\hline $\mathrm{Mn}$ & $92.11 \pm 4.75$ \\
\hline $\mathrm{Cu}$ & $93.00 \pm 3.85$ \\
\hline $\mathrm{Cr}$ & $97.04 \pm 4.68$ \\
\hline $\mathrm{Pb}$ & $85.22 \pm 10.33$ \\
\hline $\mathrm{Cd}$ & $85.45 \pm 8.75$ \\
\hline
\end{tabular}

* mean recovery \pm SD of percentage recoveries of triplicate analytes

\subsection{Metal contents of tea herb samples}

The average values of $\mathrm{Cu}, \mathrm{Cr}, \mathrm{Cd}, \mathrm{Fe}, \mathrm{Mn}, \mathrm{Zn}$ and $\mathrm{Pb}$ in selected medicinal plants are presented in Table 2.

As is evident from this table, maximum concentration of $\mathrm{Fe}$ was found in Mentha piperita $\mathrm{L}$ $333.22 \pm 35.18 \mathrm{mg} / \mathrm{kg}$ followed by Plantago major $\mathrm{L}$ $292.41 \pm 10.16 \mathrm{mg} / \mathrm{kg}$ and Matricaria camomilla $\mathrm{L}$ $291.80 \pm 5.73 \mathrm{mg} / \mathrm{kg}$.
Manganese concentrations is high in Plantago major L $166.0 \pm 5.33 \mathrm{mg} / \mathrm{kg}$, Matricaria camomilla $\mathrm{L}$ $158.0 \pm 14.33 \mathrm{mg} / \mathrm{kg}$, Mentha piperita L $148.41 \pm$ $7.24 \mathrm{mg} / \mathrm{kg}$, Hypericum perforatum $123.22 \pm 4.53$ $\mathrm{mg} / \mathrm{kg}$ and lower in other medicinal plants.

High concentrations of $\mathrm{Zn}$ was found in Matricaria camomilla L $104.8 \pm 15.24 \mathrm{mg} / \mathrm{kg}$, Achillea millefolium $126.61 \pm 12.73 \mathrm{mg} / \mathrm{kg}$, Thymus serpillum $244.90 \pm 32.13 \mathrm{mg} / \mathrm{kg}$, Taraxacum officialis L $126.76 \pm 18.29 \mathrm{mg} / \mathrm{kg}$.

Although cooper is an essential element for normal plant growth and development can be toxic at excessive levels (higher than 100 ppm dry weight).

Our analytical data revealed high concentrations of $\mathrm{Cu}$ in Plantago major L $90.96 \pm 7.89 \mathrm{mg} / \mathrm{kg}$, Mentha piperita L $56.90 \pm 8.68 \mathrm{mg} / \mathrm{kg}$ and Matricaria camomilla L $37.60 \pm 6.58 \mathrm{mg} / \mathrm{kg}$ since in other herbs we found lower levels: $6.75 \pm 0.49 \mathrm{mg} / \mathrm{kg}$ (Hypericum perforatum) and $24.6 \pm 6.46 \mathrm{mg} / \mathrm{kg}$ (Achillea millefolium).

Except two medicinal plants - Mentha piperita L and Matricaria camomilla L, potentially toxic metals $(\mathrm{Pb}$ and $\mathrm{Cd})$ were bellow the limits of detection $(0.03 \mathrm{mg} / \mathrm{kg}$ for $\mathrm{Cd}$ and $0.28 \mathrm{mg} / \mathrm{kg}$ for $\mathrm{Pb})$.

Table 2. Average values of heavy metals in investigated medicinal plants ( $\mathrm{mg} / \mathrm{kg}$ dry weight) - mean and standard error of a mean -

\begin{tabular}{|c|c|c|c|c|c|c|c|c|c|c|}
\hline Plant & \multirow{2}{*}{ Metax } & MP & HP & AM & TS & CP & UD & PO & PL & P \\
\hline $\mathrm{Fe}$ & $291.8 \pm$ & $333.22 \pm$ & $35.36 \pm$ & $90.04 \pm$ & $51.60 \pm$ & $34.20 \pm$ & $40.62 \pm$ & $92.49 \pm$ & $292.41 \pm$ & $37.69 \pm$ \\
& 5.73 & 35.18 & 3.27 & 8.53 & 6.23 & 5.78 & 3.84 & 12.85 & 10.16 & 2.34 \\
\hline $\mathrm{Zn}$ & $104.8 \pm$ & $74.61 \pm$ & $78.80 \pm$ & $126.61 \pm$ & $244.90 \pm$ & $129.26 \pm$ & $63.84 \pm$ & $74.80 \pm$ & $80.98 \pm$ & $126.76 \pm$ \\
& 15.24 & 9.68 & 9.32 & 12.73 & 32.13 & 12.38 & 14.45 & 5.33 & 5.99 & 18.29 \\
\hline $\mathrm{Mn}$ & $158.0 \pm$ & $148.41 \pm$ & $123.22 \pm$ & $45.40 \pm$ & $43.40 \pm$ & $33.55 \pm$ & $21.26 \pm$ & $19.64 \pm$ & $166.0 \pm$ & $15.34 \pm$ \\
& 14.33 & 7.24 & 4.52 & 18.83 & 5.29 & 4.02 & 2.10 & 3.08 & 5.33 & 1.88 \\
\hline $\mathrm{Cu}$ & $37.6 \pm$ & $56.80 \pm$ & $6.75 \pm$ & $24.60 \pm$ & $12.90 \pm$ & $8.22 \pm$ & $9.96 \pm$ & $7.99 \pm$ & $90.96 \pm$ & $10.70 \pm$ \\
& 6.58 & 8.68 & 0.49 & 6.46 & 1.52 & 0.30 & 1.43 & 0.29 & 7.89 & 2.44 \\
\hline $\mathrm{Cr}$ & $12.55 \pm$ & $6.80 \pm$ & $14.72 \pm$ & $6.84 \pm$ & $29.84 \pm$ & $3.30 \pm$ & $2.19 \pm$ & $28.00 \pm$ & $8.58 \pm$ & $5.21 \pm$ \\
& 0.57 & 0.96 & 1.09 & 0.36 & 6.28 & 0.52 & 0.93 & 4.19 & 5.22 & 0.42 \\
\hline $\mathrm{Pb}$ & $17.30 \pm$ & $8.04 \pm$ & $\mathrm{nd}$ & $\mathrm{nd}$ & $\mathrm{nd}$ & $\mathrm{nd}$ & $\mathrm{nd}$ & $\mathrm{nd}$ & $\mathrm{nd}$ & $\mathrm{nd}$ \\
& 5.23 & 0.96 & & & & & & & & \\
\hline $\mathrm{Cd}$ & $1.98 \pm$ & $1.56 \pm$ & nd & nd & nd & nd & nd & nd & nd & nd \\
& 1.09 & 0.28 & & & & & & & & \\
\hline
\end{tabular}

nd - not detected 


\subsection{Levels of heavy metals in tea infusion samples}

Tea infusions were also analyzed and the percentage of each element leached into the water (liquor) was evaluated. The values of concentrations of heavy metals in tea infusions are shown in Table 3.

The level of abundant essential heavy metals in tea infusion was: iron ranging from $16.88 \pm 0.87$ $\mathrm{mg} / \mathrm{L}$ (Urtica dioica $\mathrm{L}$ ) and $80.52 \pm 5.09 \mathrm{mg} / \mathrm{L}$ (Mentha piperita $\mathrm{L}$ ), followed by manganese 11.24 $\pm 0.92 \mathrm{mg} / \mathrm{L}$ (Capsela bursa-pastoris) and $55.66 \pm$ $5.38 \mathrm{mg} / \mathrm{L}$ (Hypericum perforatum). No significant difference between the concentrations of zinc into tea infusions was found. Maximum level of zinc concentration was in Taraxacum officinalis $\mathrm{L}$ tea, $49.31 \pm 2.24 \mathrm{mg} / \mathrm{L}$.

Mean concentrations of cooper and chromium ranged between $2.11 \pm 0.11 \mathrm{mg} / \mathrm{L}$ (Achillea millefolium) and $16.99 \pm 2.10 \mathrm{mg} / \mathrm{L}$ (Plantago major L) and $1.75 \pm 0.13 \mathrm{mg} / \mathrm{L}$ (Capsela bursa-pastoris) $11.08 \pm 3.07 \mathrm{mg} / \mathrm{L}$ (Primula veris $\mathrm{L}$ ) respectively.

\subsection{Efficiency of extraction from tea herbs to tea infusions}

The amount of mineral in tea infusion depends on extraction efficiencies and total concentration of metals in tea powder. Extraction coefficient is defined by the equation:
$\mathrm{EC}=100 \mathrm{x} \frac{C M(\text { extract })}{C M(\text { plant })} \mathrm{CM}-$ metal concentration

Table 4 shows the percentage of metals extracted from the tea herbs to tea infusion and these values were found to vary widely. The extraction was highest for $\mathrm{Fe}(81.95 \%)$ and lowest for $\mathrm{Cu}$ $(7.31 \%)$. The other metals were also extracted to significant degree: $\mathrm{Cr}-83.56 \%$ (Urtica dioica $\mathrm{L}$ ), $\mathrm{Mn}-70.46 \%$ (Urtica dioica $\mathrm{L}$ ).

Figure 1 shows the difference in heavy metals contents for teas of MC, MP, UD, HP, PL and their infusions.

It is evident that heavy metals content of medicinal herbs and their infusions shows variability. Distribution of the elements in the infusion is not high and is not detected especially for $\mathrm{Pb}$ and $\mathrm{Cd}$.

For $\mathrm{p}>0.05$ the difference in the samples of each particular metal was not significant.

The difference in the level of $\mathrm{Fe}(\mathrm{F}=4985.55$; $\mathrm{df}=8 ; \mathrm{p}<0.05), \mathrm{Mn}(\mathrm{F}=349.893 ; \mathrm{df}=8 ; \mathrm{p}<0.05), \mathrm{Cu}$ $(\mathrm{F}=99.491 ; \mathrm{df}=8 ; \mathrm{p}<0.05)$ and $\mathrm{Zn}(\mathrm{F}=108.308 ; \mathrm{df}=8$; $\mathrm{p}<0.05)$ in Mentha piperita L and Capsela bursapastoris was found to be significant.

In Thymus serpillum and Primula veris $\mathrm{L}$ the level of $\mathrm{Fe}(\mathrm{F}=16.007 ; \mathrm{df}=8 ; \mathrm{p}<0.05), \mathrm{Mn}(\mathrm{F}=75.34$; $\mathrm{df}=8 ; \mathrm{p}<0.05), \mathrm{Zn}(\mathrm{F}=106.234 ; \mathrm{df}=8 ; \mathrm{p}<0.05)$ and $\mathrm{Cu} \quad(\mathrm{F}=50.351 ; \mathrm{df}=8 ; \mathrm{p}<0.05)$ was significant differences.

Table 3. The level of heavy metals in tea infusions of studied medicinal plants (mg/L) - mean and standard error of a mean -

\begin{tabular}{|c|c|c|c|c|c|c|c|c|c|c|}
\hline $\begin{array}{c}\text { Plant } \\
\text { Metał }\end{array}$ & $\mathrm{MC}$ & $\mathrm{MP}$ & $\mathrm{HP}$ & $\mathrm{AM}$ & $\mathrm{TS}$ & $\mathrm{CP}$ & $\mathrm{UD}$ & $\mathrm{PO}$ & $\mathrm{PL}$ & $\mathrm{P}$ \\
\hline $\mathrm{Fe}$ & $57.96 \pm$ & $80.52 \pm$ & $10.23 \pm$ & $36.19 \pm$ & $22.08 \pm$ & $30.48 \pm$ & $16.88 \pm$ & $64.60 \pm$ & $43.71 \pm$ & $31.11 \pm$ \\
& 8.53 & 5.09 & 1.28 & 2.74 & 1.21 & 1.51 & 0.87 & 3.74 & 5.59 & 1.33 \\
\hline $\mathrm{Zn}$ & $28.76 \pm$ & $19.14 \pm$ & $13.94 \pm$ & $12.78 \pm$ & $29.84 \pm$ & $35.07 \pm$ & $30.41 \pm$ & $31.92 \pm$ & $30.63 \pm$ & $49.31 \pm$ \\
& 3.43 & 2.32 & 0.96 & 1.68 & 2.08 & 4.89 & 5.05 & 4.39 & 2.73 & 2.24 \\
\hline $\mathrm{Mn}$ & $26.11 \pm$ & $25.67 \pm$ & $55.66 \pm$ & $20.28 \pm$ & $20.54 \pm$ & $11.24 \pm$ & $14.98 \pm$ & $13.03 \pm$ & $29.58 \pm$ & $14.31 \pm$ \\
& 2.75 & 0.98 & 5.38 & 1.60 & 1.54 & 0.92 & 0.49 & 1.15 & 1.76 & 0.34 \\
\hline $\mathrm{Cu}$ & $3.63 \pm$ & $4.15 \pm$ & $3.33 \pm$ & $2.11 \pm$ & $2.11 \pm$ & $6.13 \pm$ & $6.84 \pm$ & $6.66 \pm$ & $16.99 \pm$ & $2.68 \pm$ \\
& 6.86 & 0.25 & 0.64 & 0.11 & 0.22 & 1.23 & 0.44 & 0.59 & 2.10 & 0.31 \\
\hline $\mathrm{Cr}$ & $3.27 \pm$ & $2.67 \pm$ & $1.84 \pm$ & $5.20 \pm$ & $10.44 \pm$ & $1.75 \pm$ & $1.83 \pm$ & $11.08 \pm$ & $5.57 \pm$ & $3.76 \pm$ \\
& 1.95 & 0.84 & 0.82 & 1.16 & 0.80 & 0.13 & 0.15 & 3.07 & 0.65 & 0.68 \\
\hline
\end{tabular}


Table 4. Extraction efficiency of heavy metals from medicinal plants (\%)

\begin{tabular}{|c|c|c|c|c|c|c|c|c|}
\hline \multirow[t]{2}{*}{ Metal } & \multicolumn{8}{|c|}{ Medicinal plants } \\
\hline & $\mathrm{HP}$ & MP & $\mathrm{MC}$ & UD & $\mathrm{P}$ & AM & TS & $\mathrm{PL}$ \\
\hline $\mathrm{Zn}$ & 17.69 & 25.65 & 27.44 & 47.63 & 38.90 & 10.09 & 12.18 & 37.82 \\
\hline $\mathrm{Cu}$ & 43.33 & 7.31 & 9.65 & 67.67 & 25.05 & 8.58 & 16.36 & 18.68 \\
\hline $\mathrm{Mn}$ & 45.17 & 17.30 & 16.53 & 70.46 & 53.29 & 44.67 & 47.33 & 17.82 \\
\hline $\mathrm{Fe}$ & 28.93 & 24.16 & 19.86 & 41.36 & 81.95 & 42.79 & 42.79 & 14.94 \\
\hline $\mathrm{Cr}$ & 12.50 & 39.26 & 26.86 & 83.56 & 72.17 & 34.94 & 34.99 & 64.92 \\
\hline
\end{tabular}
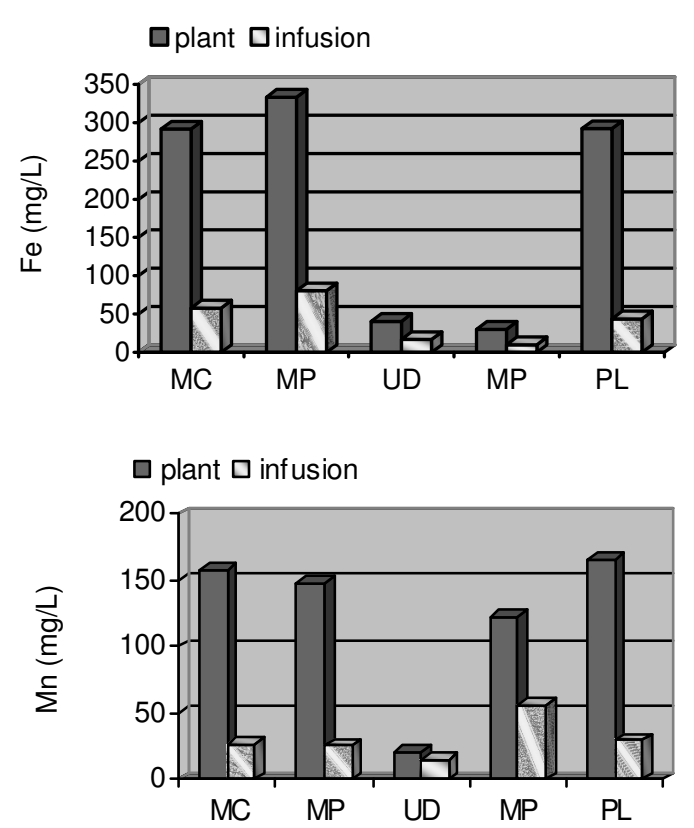

$\square$ plant $\square$ infusion

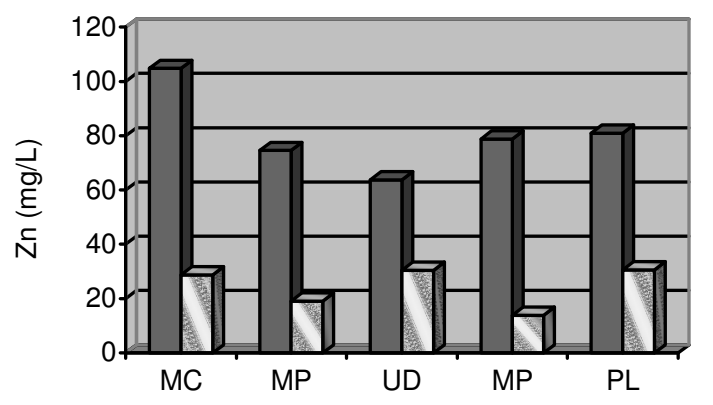

Fig. 1. Average values of $\mathrm{Fe}, \mathrm{Mn}$ and $\mathrm{Zn}$ in some plants and their infusions

In tea infusions prepared in laboratory conditions there are significant differences in metal contents as those found in the combinations of studied medicinal plants, excepting $\mathrm{Zn}, \mathrm{Cu}$ and $\mathrm{Cr}$ for some combinations of plants: Urtica dioica $\mathrm{L}$ and Primula veris $\mathrm{L}(\mathrm{Zn}: \mathrm{F}=0.255 ; \mathrm{df}=8 ; \mathrm{p}>0.05$; $\mathrm{Cu}: \mathrm{F}=0.031 ; \mathrm{df}=8 ; \mathrm{p}>0.05) ;$ Thymus serpillum and Primula veris $\mathrm{L}(\mathrm{Zn}: \mathrm{F}=0.917 ; \mathrm{df}=8 ; \mathrm{p}>0.05 ; \mathrm{Cr}$ : $\mathrm{F}=0.0204 ; \mathrm{df}=8 ; \mathrm{p}>0.05)$. In infusions obtained from Mentha piperita $\mathrm{L}$ and Matricaria camomilla $\mathrm{L}$ the levels of $\mathrm{Mn}$ : $\mathrm{F}=0.114 ; \mathrm{df}=8 ; \mathrm{p}>0.05 ; \mathrm{Cu}: \mathrm{F}=1.706$; $\mathrm{df}=8 ; \mathrm{p}>0.05$ and $\mathrm{Cr}: \mathrm{F}=0.891 ; \mathrm{df}=8 ; \mathrm{p}>0.05$ not differ significantly (Table 5).

Essential $(\mathrm{Fe}, \mathrm{Mn}, \mathrm{Zn}, \mathrm{Cu}, \mathrm{Cr})$ and toxic $(\mathrm{Pb}$, Cd) heavy metals were quantified in ten medicinal herbs and their infusions used in Romania.

The levels of $\mathrm{Fe}, \mathrm{Mn}$ and $\mathrm{Zn}$ in all plant samples were higher than other elements $(\mathrm{Cu}, \mathrm{Pb}, \mathrm{Cd})$. In two herbal samples - Mentha piperita L and Matricaria camomilla $\mathrm{L}$ the highest concentration of $\mathrm{Fe}(>200$ $\mathrm{mg} / \mathrm{kg}), \mathrm{Mn}(>100 \mathrm{mg} / \mathrm{kg})$ and $\mathrm{Zn}(>100 \mathrm{mg} / \mathrm{kg})$ was found.

Some researchers have detected higher levels of $\mathrm{Pb}$ and $\mathrm{Cd}$ in medicinal plants in areas affected pollution: mint - $\mathrm{Pb} \max 46.15 \mathrm{mg} / \mathrm{kg}, \mathrm{Cd} \max 1.20$ $\mathrm{mg} / \mathrm{kg}$, camomilla - $\mathrm{Pb} \max 25.23 \mathrm{mg} / \mathrm{kg}, \mathrm{Cd} \max$ $1.95 \mathrm{mg} / \mathrm{kg}$ [11]. In these medicinal plants, we found the lowest level of $\mathrm{Pb}$ and $\mathrm{Cd}$ (Table 2).

Recent studies shown that St. John's wort can accumulate higher contents of $\mathrm{Cd}$ than other plants grown under the dame conditions [12]. In the present study we have not noticed the same thing.

Our analytical results were close to the ones of other Romanian researchers, especially regarding the presence of $\mathrm{Fe}$ and $\mathrm{Mn}$ into medicinal plants: Matricaria camomilla L and Urtica dioica L [13].

The content of microelements into phytotherapeutic extracts - infusion of the studied plant materials has been investigated. Most elements in these herbal tea powders were released into infusion at different percentages depending to types of plants. 
Table 5. Statistics differences in tea infusions obtained from different combinations of tea herbs

\begin{tabular}{|c|c|c|c|c|c|c|c|}
\hline Metal & MP $v s$ MC & MP $v s$ AM & TS $v s$ CP & UD vs PO & PL $v s$ P & TS vs PO & MP $v s$ CP \\
\hline $\mathrm{Fe}$ & 0.001 & 0.000 & 0.000 & 0.000 & 0.001 & 0.000 & 0.000 \\
\hline $\mathrm{Mn}$ & 0.746 & 0.000 & 0.000 & 0.008 & 0.000 & 0.000 & 0.000 \\
\hline $\mathrm{Zn}$ & 0.001 & 0.050 & 0.050 & 0.621 & 0.000 & 0.360 & 0.046 \\
\hline $\mathrm{Cu}$ & 0.230 & 0.000 & 0.000 & 0.814 & 0.000 & 0.000 & 0.006 \\
\hline $\mathrm{Cr}$ & 0.374 & 0.000 & 0.000 & 0.000 & 0.003 & 0.664 & 0.019 \\
\hline
\end{tabular}

Water extraction from medicinal plants allows passing only of a part of quantity present in plants, the percent of extraction are between $7.31 \%$ to $83.56 \%$ and registered variations. In tea infusion, Fe was the most predominant (14.94-81.95\%) followed by Mn (17.3270.46\%), $\mathrm{Cr}(12.50-83.56 \%)$ and $\mathrm{Cu}(7.31-67.67 \%)$. The amount of minerals in tea infusions depends on extraction efficiencies. We classified elements in three groups:

- highly extractable elements (>55\%): e.g. $\mathrm{Mn}, \mathrm{Cr}, \mathrm{Fe}$;

- moderately extractable elements (30-55\%): e.g. Zn, $\mathrm{Cu}$;

- poorly extractable elements $(<30 \%)>$ e.g. Cd, $\mathrm{Pb} . \mathrm{We}$ observe that, there is no perfect correlation between the levels of metals in different herbs and their infusions. A positive correlation was especially to $\mathrm{Fe}(\mathrm{r}=0.9858)$ and $\mathrm{Cr}(\mathrm{r}=0.8869)$ for Matricaria camomilla $\mathrm{L}$.

\section{Conclusions}

The metallic elements $\mathrm{Cu}, \mathrm{Cr}, \mathrm{Cd}, \mathrm{Fe}, \mathrm{Mn}, \mathrm{Pb}$, $\mathrm{Zn}$ contained in ten medicinal plants showed a wide variability. Iron is the metal present in large amount followed by $\mathrm{Mn}, \mathrm{Zn}$ and $\mathrm{Cu}$. The very low concentrations of $\mathrm{Pb}$ and $\mathrm{Cd}$ only in two medicinal plants we found.

Analysis of plant infusions showed transfer of heavy metals during extraction procedure, extraction coefficients reached values up to $70-80 \%$ depending on the treated plant species. The highest content of $\mathrm{Fe}$ transported to the infusion came from Taraxacum officinalis (81.95\%), Thymus serpillum (42.79\%) and Urtica dioica L (41.36\%).

The studied metals could be arranged in decreasing order according to their contents in tea herbs as following:

$$
\mathrm{Fe}>\mathrm{Zn}>\mathrm{Mn}>\mathrm{Cu}>\mathrm{Cr}
$$

In general, metal contents of medicinal plants were found to be higher than those of tea infusion.

Summarizing the obtaining results shows that toxic metals $(\mathrm{Pb}$ and $\mathrm{Cd})$ were insoluble in all infusions, and thus do not pose any risks in terms of toxic metals in diet. The strongest positive correlations between the concentrations of two metals, in Matricaria camomilla L and its infusion for $\mathrm{Fe}$ and $\mathrm{Cr}$, was registered.

The accurate determinations of metallic elements in medicinal plants and their infusions were very important in assessing any potential implications for human health.

\section{References}

*E-mail address: rodiaconu@yahoo.com

[1] M.T. Soomro and E. Zahir, Pak J Biol Sci. 11:285-289 (2008).

[2] T. Karak and R.M. Bhagat, Food Res Intern, 43, 2234-2252 (2010).

[3] G. Karimi, M.K. Hasanzadeh and A. Nili Pharmacologyonline 3, 164-178 (2008).

[4] F.M. Shen and H.C. Wen, Bull Environ Contam Toxicol. 80, 300-304 (2008).

[5] S.A. Nasim and B. Dhir, Rev Environ Contam Toxicol, 203, 139-149 (2010).

[6] H. Sarmo, S. Deka and R.R. Saikia, Rev Environ Contam Toxicol, 214, 63-66 (2011).

[7] M.R. Gomez, S. Cerntti and R.A. Olsina. J Pharm Biomed Anal, 3, 42-46 (2004).

[8] I. Hussain, F. Khan, I. Khan and L. Khan, J Chem Soc of Pak, 28(4), 347-351 (2006).

[9] S.K. Dwivedi and S. Dey, Arch Environ Health, 57 (3), 229-231 (2002).

[10] S. Haider, V. Naithani and J. Barthwal, Bull Environ Contam Toxicol, 72 (1), 119-127 (2004).

[11]I. Baranowska, K. Srogi, A. Wlochowicz and K. Szczepanik, pol J of Environ Studies, 11 (5), 467-471 (2002).

[12] E. Caldas and L. Machado, Food and Chem Toxicol, 42 (4), 599-603, (2004).

[13] S. Dobrinaş, A.D. Soceanu, G. Stanciu and S. Bratu, Ovidius Univ Annals of Chem, 22 (1), 37-40 (2011).

Submitted: March $6^{\text {th }} 2012$ Accepted in revised form: April $30^{\text {th }} 2012$ 